\title{
IDEOLOGÍAS LINGÜÍSTICAS ACERCA DEL MAPUDUNGUN EN LA URBE CHILENA: EL SABER TRADICIONAL Y SU APLICACIÓN A LA REVITALIZACIÓN LINGÜÍSTICA
}

\author{
LANGUAGE IDEOLOGIES ABOUT MAPUDUNGUN IN CHILEAN CITIES: \\ TRADITIONAL KNOWLEDGE ANT ITS APPLICATION TO \\ LANGUAGE REVITALIZATION
}

\author{
Darío Rojas $^{1 *}$, Cristián Lagos ${ }^{1}$ y Marco Espinoza ${ }^{1}$
}

\begin{abstract}
En el marco de la antropología lingüística, y considerando su aplicación a la planificación del lenguaje y las lenguas, analizamos las representaciones sociales acerca del mapudungun asociadas al saber tradicional, considerándolas como ideologías lingüísticas. En particular, nos enfocamos en aspectos relacionados con la revitalización de esta lengua en contextos urbanos de Chile. Contrastando estas representaciones con las que en otros estudios hemos hallado sobre el tema, constatamos que, mientras las ideologías lingüísticas de los especialistas dan mayor importancia a la planificación del corpus y a la enseñanza de la lengua en la escuela y talleres, las reflexiones enunciadas desde el saber tradicional ponen énfasis en el cultivo del estatus lingüístico y la promoción social de la lengua, así como en la centralidad de la recuperación de los circuitos tradicionales de reproducción (familia y comunidad) como clave para rescatar el mapudungun. Proponemos que la revitalización de esta lengua podría verse beneficiada al tomar en cuenta el saber tradicional, pues permitiría equilibrar las diversas facetas de una actividad tan compleja como es la planificación lingüística indígena.
\end{abstract}

Palabras claves: mapudungun, ideologías lingüísticas, antropología lingüística, revitalización lingüística, mapuches urbanos.

Within the framework of linguistic anthropology and its application to language planning, we analyze the social representations about Mapudungun in traditional knowledge (i.e., the language ideologies of the members of indigenous communities), specifically about those aspects concerning the revitalization of this language in Chile. While specialists give a greater importance to corpus planning and to language teaching in schools and workshops, traditional knowledge place emphasis on the cultivation of language status and on the social promotion of their language, as well as on the recovering of traditional spaces of language reproduction (the family and the community). We propose that the revitalization of Mapudungun could benefit from taking into account traditional knowledge, for this would allow to balance the different facets of such a complex enterprise as indigenous language planning.

Key words: Mapudungun, language ideologies, linguistic anthropology, language revitalization, urban Mapuche.

En el presente trabajo mostramos resultados de un conjunto de investigaciones ${ }^{1}$ en que nos hemos propuesto describir las representaciones sociales que los mapuches urbanos de Chile, poseedores de distintos niveles de competencia en mapudungun, tienen acerca de esta lengua.

Consideramos que el conocimiento de los modelos culturales que los propios miembros de los pueblos originarios tienen acerca de sus lenguas contribuye, en primer lugar, al perfeccionamiento de diversas aplicaciones de la lingüística, entre las que sobresale la planificación lingüística. Entendemos por esto una forma específica de planificación social (Amorós 2008:18), que comprende distintos tipos de intervenciones que afectan a los usos lingüísticos de una comunidad, tales como planificación de corpus, planificación de estatus, planificación de adquisición, planificación de educación lingüística y planificación de imagen o prestigio (Hornberger 2006). Cabe destacar, además, que la planificación lingüística no concierne únicamente al lenguaje, pues en ella se entremezclan factores de tipo económico y político, entre otros (Ricento 2006:8). Según nuestro concepto, es clave destacar la importancia que tiene para la planificación lingüística la interacción entre los agentes y sujetos de la planificación, por un lado, y las ideologías lingüísticas que sostienen ambos, por el otro.

\footnotetext{
1 Departamento de Lingüística, Facultad de Filosofía y Humanidades, Universidad de Chile, Santiago, Chile. Dirección postal: Av. Capitán Ignacio Carrera Pinto 1025, piso 3, Ñuñoa, Santiago, RM, Chile, C. P. 7800284. darioroj@u.uchile.cl *autor correspondiente; crlagos@uchile.cl; mespinozalv@gmail.com
} 
En segundo término, contribuye a completar y mejorar el conocimiento científico de la naturaleza de las lenguas. En este último sentido, especialmente, la aproximación teóricometodológica de la lingüística popular se plantea como una propuesta de revalorizar los saberes y reflexiones tradicionales que pueden manifestar las comunidades en relación con su instrumento comunicativo. Estos saberes resultan especialmente iluminadores si se los contrasta con el discurso de los especialistas, pues ponen énfasis en aspectos que estos últimos a veces descuidan, tal como sucede en el caso de la lengua mapuche.

En los apartados siguientes abordaremos, primero, la pertinencia del enfoque teóricometodológico de la lingüística popular y del concepto de ideología lingüística, aplicados a la revitalización y promoción del mapudungun, así como la situación actual del mapudungun en la urbe chilena. Tras explicar el método empleado en nuestro estudio, ofreceremos una primera aproximación a los discursos que emanan desde el saber tradicional respecto del mapudungun, con el fin de resaltar aquellos tópicos más recurrentes y las implicancias de estos para los procesos de promoción y revitalización de la lengua mapuche, contrastándolos con el discurso de los mapuches que tienen formación o participación como especialistas en asuntos lingüísticos.

\section{Marco Conceptual}

\section{Lingüística popular (aplicada) e ideologías lingüísticas}

El enfoque conocido como lingüística popular tiene por objetivo principal describir los modelos culturales que los no lingüistas tienen acerca del lenguaje, es decir, describir las teorías lingüísticas populares (Niedzielski y Preston 2003), que a lo largo del presente estudio denominaremos "saberes (metalingüísticos) tradicionales". La lingüística popular tiene la particularidad de proponer una revalorización de los saberes tradicionales y de las reflexiones de quienes no son lingüistas (Paveau 2011), que tradicionalmente han sido marginados como meras confusiones o malentendidos acerca del lenguaje o bien como "mitos lingüísticos" (Bauer y Trudgill 1998). El uso del adjetivo popular (folk, en el original inglés) no conlleva una valoración negativa: simplemente se refiere a "aquellos que no poseen entrenamiento profesional en el área que se investiga [lingüística, en este caso]" (Niedzielski y Preston 2003:xviii) ${ }^{2}$. Por otra parte, la lingüística popular problematiza la distinción binaria entre lingüistas y no lingüistas, proponiendo en su lugar la consideración de un continuo determinado por la construcción social de estos roles entre diversos miembros de la comunidad en situaciones específicas (Wilton y Stegu 2011). En este sentido, tanto los discursos metalingüísticos de los lingüistas profesionales como los de los hablantes sin formación especializada estarían igualmente anclados a intereses particulares y a grupos específicos, de modo que surge una relativización del valor de "verdad" que habitualmente se atribuye al discurso de los especialistas, debido principalmente a su vinculación con estructuras de poder sociopolítico. Por esta misma razón, tampoco se trata de intentar transformar los saberes tradicionales en una "nueva verdad", pues sería simplemente invertir los polos de la estructura de poder. En nuestro estudio, asumimos que el objetivo de esta postura no es suplantar una voz dominante por otra, sino integrar las voces de los hablantes comunes y corrientes al diálogo acerca de problemas que les competen directamente.

Entre los motivos que justifican una lingüística popular, sobresale su potencial de aplicación a la resolución de problemas concretos con que se enfrentan los hablantes, de modo que hoy se habla, con propiedad, de una lingüística popular aplicada (Wilton y Stegu 2011). Entre estos problemas destacan la planificación lingüística y la enseñanza de lenguas. Por ejemplo, al momento de implementar un proceso de estandarización o de revitalización lingüística, es fundamental que los agentes planificadores "estén bien informados [...] acerca de las necesidades y las percepciones de la sociedad o comunidad de habla en cuestión" (Wilton y Stegu 2011:11), para tener una idea de cómo los sujetos reaccionarán ante las medidas glotopolíticas que se adopten. Por otra parte, la enseñanza/aprendizaje de lenguas (actividad también relevante en la revitalización de una lengua minorizada) se puede beneficiar significativamente de la consideración de, por ejemplo, cómo aprendientes y profesores conciben el lenguaje o cómo piensan que se adquiere un idioma (Pasquale 2011).

Los sistemas de creencias que se propone develar la lingüística popular han sido estudiados también como ideologías lingüísticas (Kroskrity 2010) o culturas lingüísticas (Schiffman 1996), tomando en préstamo de la sicología social, de la antropología 
y de la sociología las nociones de modelo cultural, representación social e ideología y aplicándolas al estudio de las ideas acerca del lenguaje en cuanto producto de la cultura. Todas estas aproximaciones comparten una perspectiva antropológica acerca del lenguaje. Por nuestra parte, consideramos útil complementar el enfoque epistemológico de la lingüística popular con las propuestas de los estudios de ideologías lingüísticas, que ponen énfasis en la naturaleza social e históricamente situada de los modelos culturales acerca del lenguaje. Aunque el concepto de ideología ha adquirido sentidos y connotaciones variadas (Silverstein 1998:123-125), en la corriente de estudios lingüístico-antropológicos se asume una perspectiva fundamentalmente sociocognitiva (afín a la de Van Dijk 1998) y no evaluativa en términos de la "factualidad" de los sistemas de creencias compartidos por un grupo humano (Woolard 1998:7-9).

Nos parece especialmente interesante aproximarnos a la planificación de las lenguas indígenas en Chile desde el punto de vista de las ideologías, además, porque en los últimos años se ha llamado la atención sobre la necesidad de estudiar la variación cultural de las ideologías lingüísticas (Blommaert 2006:518-519). La mayoría de los estudios sobre los modelos culturales acerca del lenguaje se basa en un grupo reducido de lenguas modernas europeas, tales como el inglés, el alemán, el español o el francés. Milroy (2001:543-547) señala que incluso la manera en que los lingüistas profesionales conciben el lenguaje actualmente ha sido modelada a partir de la ideología de la lengua estándar, propia del mundo europeo moderno, sin que haya sido planteada la pregunta de cómo conciben el lenguaje las comunidades que hablan lenguas no estandarizadas. En contraposición a esto, Feng (2009) reclama modelos lingüísticos orientados por las ideologías de los grupos que hablan lenguas determinadas. Varios estudios (Anderson 2009; House 2002; Kroskrity 2000; Schieffelin 2000) han mostrado los efectos negativos del trasplante acrítico de las ideologías lingüísticas desde un contexto cultural a otro que presenta diferencias importantes. Sin que propongamos una especie de inconmensurabilidad intercultural, consideramos que es necesario no dar por sentado que los hablantes de mapudungun tienen modelos culturales acerca del lenguaje idénticos a los imperantes en el Chile hispanohablante, ni que todos los mapuches tienen una ideología uniforme en torno a la lengua de su pueblo. Una consideración acrítica de este asunto podría contribuir a perpetuar un círculo vicioso perjudicial para la revitalización de las lenguas indígenas de Chile en entornos urbanos, pues, como indica Romaine (2007:708), las prácticas de planificación lingüística que reproducen la ideología lingüística dominante reproducen también las estructuras de dominación vigentes.

\section{La situación del mapudungun en el contexto urbano chileno}

La realidad del mapudungun en Chile, en la historia y en la actualidad, da cuenta de dinámicas progresivas de deterioro funcional y estructural (CONADI 2005, 2008, 2010; Gundermann et al. 2009; Lagos 2004, 2006, 2009, 2011, 2012a, 2012b, 2012c; Lagos et al. 2009; Sánchez 1996; Vergara y Gundermann, 2005; Wittig 2009) que han motivado, en fechas recientes, a la acción planificada para contribuir a su promoción y revitalización efectivas. En la última década ha surgido un importante movimiento por la revitalización de las lenguas indígenas de Chile, en que participan los propios miembros de las comunidades indígenas, los especialistas, y agrupaciones como la Red por los Derechos Educativos y Lingüísticos de los Pueblos Indígenas de Chile, la Academia Nacional de la Lengua Mapuche, el Internado Lingüístico de Mapuzungun, la Federación Mapuche de Estudiantes o la Comunidad de Historia Mapuche, entre otras. Entre los logros de este movimiento se cuentan el ingreso al Senado de Chile del proyecto de ley de derechos lingüísticos de los pueblos indígenas, y la cooficialización del mapudungun en algunas comunas de la Región de la Araucanía (Padre Las Casas o Galvarino), con posible extensión futura a toda la región. Pero estos avances todavía no han logrado revertir completamente el perjuicio que ha sufrido el mapudungun (junto con las demás lenguas indígenas de Chile) a lo largo de la historia.

Tras la anexión definitiva de los territorios mapuches históricos al naciente Estado chileno en el siglo XIX, la migración masiva de su población hacia las ciudades se inició en la década de 1930. Esta migración fue gatillada por un conjunto de factores estructurales que han determinado que en la actualidad entre un 70 y un $80 \%$ de la población del país que se adscribe a este grupo indígena se encuentre residiendo en áreas urbanas, principalmente en la capital, Santiago, y en las ciudades intermedias 
de las regiones de poblamiento histórico, como Concepción, Temuco, Imperial y Carahue, entre otras. Esta nueva distribución territorial es consecuencia de la relación establecida entre ruralidad, etnicidad y pobreza, la que ha obligado a estos grupos a la búsqueda de nuevos horizontes económicos y sociales.

La migración indígena forzada tuvo carácter selectivo y fue protagonizada principalmente por jóvenes, especialmente mujeres, quienes tenían una inserción laboral más rápida y estable en el trabajo doméstico, vinculado a la reproducción de las prácticas y roles de género socialmente aprendidos en la familia y en la comunidad. Además, esta población indígena migrante fue heterogénea: se componía de diversas generaciones y sus descendientes, diferentes grupos de edades, autorreconocidos con diferentes experiencias, conocimientos y discursos sobre su identidad étnica. A su llegada al medio urbano, el mapuche migrante se encontró con una realidad distinta a la de su marco de expectativas: debido a una serie de desventajas y carencias derivadas de la situación de dominación y exclusión en la que se vieron inmersos, gran parte de los que llegaron a las ciudades terminaron viviendo en condiciones de pobreza y precariedad material, sufriendo la discriminación y la marginación social, no solo de parte de los chilenos, sino que de sus mismos pares que optaron por quedarse en la comunidad originaria (en la zona sur del país). Una vez establecidos en la ciudad, una forma, precisamente, de mantener el contacto con aquella comunidad originaria perdida fue integrarse a organizaciones mapuches urbanas (clubes deportivos, cooperativas, asociaciones gremiales, agrupaciones juveniles, de mujeres o de ancianos), las que, desde la década de 1960 comenzaron a actuar como estructuras transicionales (Munizaga 1961). La función latente de estas estructuras fue y sigue siendo morigerar los efectos del choque cultural que implica la llegada del sujeto a la capital. De esta manera, han actuado como mecanismos de integración o estabilización social, constructoras de identidad, de comunidad, en el ambiente citadino, sobre todo cuando quienes pertenecen a esta etnia indígena llegan a la ciudad y pasan a constituir barrios periféricos como espacios de marginalidad y segregación socioétnica.

Así, como consecuencia de estos procesos, en la actualidad encontramos a la población mapuche habitando mayoritariamente en ciudades y concentrada principalmente en Santiago. De hecho, según las cifras del último Censo de Vivienda y Población 2012 (INE 2013), hoy existen más mapuches viviendo en la Región Metropolitana (principalmente en Santiago) que en las regiones históricamente habitadas por esta etnia, VIII y IX Región, tomadas en conjunto (564.234 mapuches viven en la Región Metropolitana, superando a los 160.837 de la VIII Región y los 285.441 de la IX). Esta población, más allá de los procesos de reetnificación que experimenta, se relaciona con su lengua nativa mediante dinámicas heredadas de su relación histórica con el mundo huinca o chileno: una lengua minorizada frente al castellano y de la que se ha perdido el control cultural, tanto en la producción como en la reproducción lingüística, en la medida en que los mapuches (hablantes o no) en muy pocos espacios culturales pueden optar por su uso (Gundermann et al. 2009; Lagos 2006; Wittig 2009). Además, los últimos estudios en torno al tema han coincidido en señalar los bajos niveles de competencia lingüística en mapudungun que presentan los descendientes de esta etnia, sobre todo en el medio urbano (CEP 2006; Gundermann et al. 2009; Lagos 2009, 2011; Lagos et al. 2009; Mariano et al. 2010). Más aún, estudios recientes han mostrado que para la mayor parte de los mapuches, incluso en zonas rurales, el mapudungun ha perdido su estatus de lengua materna (lugar que ha pasado a ocupar el español) y ha llegado a adquirir estatus de L2 (Lagos 2012a). Esto ha sido confirmado por las cifras del último censo chileno (INE 2013), las que señalan que solo un $8,6 \%$ de quienes se identifican como mapuches se consideran capaces de tener una conversación en mapudungun.

Frente a esta situación de desplazamiento funcional, tanto huincas como mapuches (especialistas y no especialistas, hablantes y no hablantes) han generado manifestaciones discursivas (a veces traducidas a políticas públicas) tendientes a explicar las causas de este amenazante panorama, así como posibles medidas tendientes a cambiar la condición de lengua minorizada que tiene el mapudungun. Tales discursos han representado, epistémicamente, maneras de entender el fenómeno de acuerdo con el paradigma que ha dominado a quienes los han elaborado, paradigmas que es conveniente explicitar y que justifican la necesidad de incorporar los modelos culturales nativos no solo respecto de la naturaleza de su lengua, sino también respecto de cómo rescatarla. En este sentido, nos encontramos con la existencia de dos grandes tipos de discursos en torno al tema: (a) el discurso de la lingüística de 
tradición europea, junto con el de los especialistas mapuches que se han formado bajo su influencia, y (b) el discurso de los mapuches que representan los saberes tradicionales, tanto los que hablan el mapudungun como aquellos que no. La propuesta que planteamos tiene relación con la necesaria incorporación de esta segunda matriz discursiva como elemento de una planificación lingüística para el mapudungun.

\section{Metodología}

Dado que nuestro trabajo se enmarca en el espectro disciplinar mayor de la antropología lingüística, adoptamos un enfoque etnográfico general. La indagación acerca de los saberes metalingüísticos tradicionales requiere observarlos en sus contextos naturales de ocurrencia, esto es, el mundo de la vida cotidiana, en donde tales lenguas circulan. La información levantada provino de nuestra inserción en actividades de talleres de lengua realizados en la ciudad, asociaciones indígenas y escuelas (y salas de clases) en las que se desarrolla el programa de educación intercultural bilingüe en las ciudades de Santiago, Concepción y Temuco. Los participantes de nuestro estudio, por tanto, fueron los integrantes de estas agrupaciones, participantes de talleres, profesores y alumnos de ascendencia mapuche.

Hemos aplicado, con un enfoque puramente cualitativo, el análisis del discurso orientado al contenido (Preston 1994) a entrevistas y grupos de discusión en que participaron sujetos mapuches que no tienen entrenamiento especializado en el estudio del lenguaje. Igualmente, analizamos material obtenido durante trabajo etnográfico en reuniones de talleres, escuelas y otras asociaciones mapuches. Las entrevistas y grupos de discusión realizados tenían como ejes temáticos la posición de los participantes frente al proceso de deterioro funcional y estructural del mapudungun y las alternativas de solución frente a esta situación. Los participantes en este estudio corresponden principalmente a individuos que no tienen como ocupación profesional algún asunto relacionado directamente con la lengua, pero que han tenido un acercamiento al mapudungun como aprendientes en talleres u otras iniciativas similares, o bien, los menos, que la han tenido como lengua materna o segunda lengua durante gran parte de su vida. De esta manera, quienes nos reportaron sus experiencias corresponden, en términos del continuum de Paveau (2011), al polo de los "hablantes comunes y corrientes", con el menor grado de especialización, que se ubican en el extremo opuesto de los lingüistas profesionales, y que representan los saberes metalingüísticos tradicionales.

\section{Las Ideologías Lingüísticas de los Mapuches Acerca del Mapudungun}

\section{La visión de los especialistas mapuches}

Los discursos acerca del mapudungun emanados desde los saberes tradicionales pueden ser apreciados con mayor profundidad si se los contrasta con las ideas de los mapuches especialistas, es decir, aquellos mapuches que han recibido entrenamiento formal en estudios lingüísticos (de tradición europea o estadounidense, principalmente) y forman parte de una élite intelectual en universidades e instituciones similares. Son estos últimos los que, por su posición privilegiada como interlocutores entre el pueblo mapuche y el Estado chileno, han participado activamente en la política lingüística oficial que actualmente se ha implementado en Chile (en relación no solo con el mapudungun). Por esta razón, haremos una breve reseña de los hallazgos de algunos de nuestros estudios anteriores sobre el tema (Lagos 2012b; Lagos et al. 2013).

Buena parte de los especialistas mapuches se han convertido en voceros de representaciones sociales e ideologías lingüísticas comprometidas con el evolucionismo decimonónico y el ideal estandarizador y homogeneizador propio de la tradición lingüística de raigambre europea y de corte racional iluminista (Bourdieu 2001; Foucault 1966). Estos especialistas se han formado en el marco de dicha tradición (en su mayoría son y han sido profesores de universidades chilenas), desde donde han asimilado matrices culturales que han guiado su reflexión en torno a su lengua nativa y las vías para recuperarla. Como resultado, su actividad tanto en agrupaciones indígenas como en universidades y centros de pensamiento ha resultado en ideologías lingüísticas, en el mejor de los casos, representativas de un sincretismo mapuche-chileno, ciertamente asimétrico a favor de la visión racionalista propia de la lingüística europea.

Dos tópicos concentran la atención de los especialistas mapuches: el grafemario y la enseñanza de la lengua. En cuanto al primero, se piensa (con un 
sesgo evolucionista) en "rescatar" al mapudungun de su condición de lengua ágrafa, para hacer entrar esta lengua en las "grandes ligas", tal como se puede inferir del discurso de algunos intelectuales mapuches influyentes (Chiodi y Loncón 1995; Painemal 2007). Como consecuencia, por más de 30 años se han invertido recursos humanos y financieros en el problema del grafemario, sin lograr resolver las diferencias de opinión. No podríamos negar la importancia de este aspecto, pero, como hemos podido ver, parecen haber otros asuntos más urgentes que resolver, señalados por los no especialistas. Tampoco, por otra parte, puede pensarse que el único aspecto importante de la planificación de corpus es la elaboración de un grafemario.

En cuanto al énfasis que los mapuches especialistas ponen en aumentar la oferta de la enseñanza de la lengua (véase, por ejemplo, Loncón 2002), creemos que revela una visión de la vitalidad lingüística que la reduce a las instancias de enseñanza (independientemente de su éxito) y al (potencial) número de hablantes de la lengua y que omite un hecho fundamental, reconocido, paradójicamente, por los saberes tradicionales: la recuperación de la lengua debe abrirse también a incluir la necesidad de luchar por espacios legitimados de uso de la lengua, de tal manera que su enseñanza adquiera sentido al dotar de funcionalidad efectiva al idioma. Múltiples esfuerzos, de esta manera, se han consagrado a abrir cada vez más talleres de lengua, a formar cada vez más educadores de lengua y aumentar la oferta de enseñanza y a generar manuales para la enseñanza del mapudungun en espacios no tradicionales, como escuelas y talleres (Mariano et al. 2013; Vergara y Salazar 2012). Sin embargo, la enseñanza de la lengua, en la práctica, sigue girando en gran medida en torno a los lineamientos del Decreto 280 del Ministerio de Educación chileno, marco legal que define la planificación lingüística indígena en el ámbito escolar, independientemente de la voluntad de los actores sociales directamente involucrados en el movimiento de revitalización del mapudungun.

\section{Los discursos erigidos sobre el saber tradicional: el mapudungun como clave para la reetnificación}

\section{El valor del mapudungun}

Si nos guiáramos por el universo conceptual en torno a la relación entre lengua y cultura propuesto por Salas (1985) para el mapudungun, que señalaba que "hablar en mapuche es vivir en mapuche", la mayor parte de los participantes de nuestro estudio habrían dejado de ser socioculturalmente mapuches al haberse castellanizado en la ciudad y haber asumido modos de vida que los asimilan al resto de los chilenos (Wittig 2009). Sin embargo, los discursos de mapuches no pertenecientes a la élite intelectual y que, en distinto grado, participan de agrupaciones urbanas que buscan recuperar la lengua y cultura de esta etnia o asisten a talleres de enseñanza de mapudungun, dan cuenta de un panorama diferente, construido en torno a representaciones sobre la lengua. Estos nuevos actores sociales estructuran su identidad mapuche urbana desde otras coordenadas, en las que, si bien la lengua no es un elemento actualizado como instrumento para la comunicación efectiva, sí está presente como una herramienta simbólica para construir un horizonte de sentido respecto de lo que es ser mapuche en la ciudad, en la actualidad.

Los mapuches que han migrado a la ciudad, o que han nacido en ella, han generado una serie de representaciones sociales en torno al mapudungun, en las que, a pesar de que su nivel de competencia en esta lengua sea nulo o muy bajo (Mariano et al. 2010), ella sigue jugando un rol central en su identidad como comunidad. Por esto, reflexionar sobre la situación del mapudungun es también una oportunidad para reflexionar sobre su condición de indígenas urbanos. Este nuevo mapuche, nacido y educado en la ciudad, tal vez no tenga la apariencia externa de uno tradicional, pero manifiesta su resistencia hacia los procesos de creciente desetnificación a través de la valoración y rescate de su lengua. La pérdida histórica de la tierra, en tanto medio de producción y relación simbólica, asociada a los procesos de migración forzada a la ciudad para convertirse en una población obrera, productores de materia prima o trabajadores de casas (aseo, jardinería, cocina, etc.), y la actual situación de resurgimiento de la valoración de su condición étnica generada desde el retorno a la vida democrática en la última década del siglo XX, han generado en los actores sociales indígenas la necesidad de recurrir a diversos aspectos simbólicos desde los cuales construir su identidad: la tierra (solo a nivel simbólico), la sangre, la vestimenta, los sueños (peuma) y, finalmente, la lengua. Esta última es el elemento nuclear señalado por los mapuches urbanos para reconocerse a sí mismos y ante sus pares como representante fiel 
de su comunidad originaria, como lo señaló uno de nuestros entrevistados:

[...] si uno no prefiere hablar en mapuche yo creo que ya no nos sentiríamos mapuches [...] los mapuches estamos en todas partes [...] y si no lo habláramos, o sea, uno ve siquiera con la vestimenta se siente hermano [...] y con mayor razón si hablamos la lengua (L. M.).

Es en su participación en el espacio ritual y ceremonial donde la lengua refuerza su rol identitario. Esto es un acicate para conocerla, por tanto:

\section{[...] los nguillatunes, que son la ceremonia} religiosa más importante [...] todo se habla en ese idioma, tú te comunicas con las fuerzas que hay en el mundo con ese idioma [...] entonces es algo súper importante, si tú quieres pedirle [...] a Ngenechen, que es el dios, y tú no se lo puedes hacer en español [...]. Tienes que hablarlo en el idioma nuestro [...] (M. P.).

Además, el mapudungun, y su recuperación por parte de los mapuches urbanos, es concebido como la posibilidad de volver a comunicarse con su comunidad de origen: el sur. Este territorio es construido simbólicamente como un espacio de preservación de lo mapuche en sus manifestaciones más originales y puras. Así se evidencia en el discurso de esta mujer, la que recuerda:

[...] para mi papá es rememorar todo lo que fue su infancia, porque, en el fondo, a él le enseñó a hablar su abuelo, y él habla mapudungun con la gente cuando está en el sur, o sea, para él es hacer un retroceso en la vida y llegar a lo que fue su infancia [...] (C. S.).

Además, el sur aparece como un espacio de reproducción de la lengua, un lugar donde siempre se puede volver a aprender:

[...] el que no sabe hablar bien, uno le dice, no po', y volví' para atrás, así se dice, ah, ya, dice uno [...] cuando estamos ahí es como que nosotros volvimos a ser mapuches y como que estamos allá en la tierra natal [...] (F. H.).

Observamos, así, que en los discursos analizados emerge un mapuche nacido en la ciudad y educado en las matrices culturales propias de la sociedad nacional chilena hispanohablante (de hecho, son los estudiantes de educación superior de origen mapuche los que con más fuerza reflejan esta situación), que es capaz de revertir los procesos de desetnificación hacia los cuales los lleva la dinámica social actual (integrarse plenamente), mediante el descubrimiento y la reconstrucción de su origen, de su calidad de indígena mapuche. En esa tarea de reconstrucción, habiéndose perdido la tierra, aprender mapudungun aparece como una forma de resistencia frente a las condicionantes que le impone la sociedad chilena. Es este sincretismo entre inquietud lingüística, cultural y política el que asegura, por lo menos en una escala temporal amplia, la supervivencia de la lengua mapuche, aunque en la actualidad la competencia declarada sea tan baja como la mostrada (Mariano et al. 2010). Vemos así, que el plano de las representaciones sociales permite que la lengua sea revalorizada por las nuevas generaciones, asegurando su continuidad (por el momento).

\section{Explicaciones para el estatus del mapudungun como lengua "amenazada"}

Si bien la situación de pérdida de vitalidad de la lengua mapuche se puede explicar por las mismas condicionantes que comparten las lenguas amerindias en tanto lenguas amenazadas, los discursos de los mapuches urbanos entregan una nueva clave que permite identificar una causa central: la pérdida y ruptura de los circuitos tradicionales de producción y reproducción de la lengua. Este fenómeno se explica en virtud de los siguientes factores:

(a) La pérdida de la familia como espacio social de reproducción de la lengua, lo que podemos ejemplificar en un caso que resulta paradigmático: ella, una machi, y su marido eran monolingües en mapudungun en su comunidad de origen. Llegaron a Santiago y mantuvieron la lengua entre ambos. Sin embargo, ninguno de sus hijos la habla, debido a que su familia dejó de ser espacio de reproducción lingüística: 
[...] conversábamos porque igual era indígena el finado de mi marido, porque falleció después, falleció aquí. Y hablábamos los dos, menos los hijos, no saben, porque los hijos no, no saben hablar el idioma como hablo yo, porque ellos nacieron aquí también, los demás [que] traje de allá chicos, tampoco [hablan], olvidaron [...] ahora hablan puro chilenazo [español] [...] cuando nacen aquí no saben hablar. Igual sabían hablar y perdieron todo (V. G., paréntesis nuestros).

Uno de los factores que explican esta situación es la experiencia de discriminación (o la expectativa de sufrirla) en la ciudad, sobre todo en la escuela. Esta discriminación, a su vez, se encuentra muy asociada a la pérdida de redes sociales, factor que extiende los problemas de reproducción de la lengua al nivel de la comunidad, al impedirle tener espacios donde reproducir su lengua, algo que no sucedía en la comunidad de origen. Otro factor incidente es la pérdida de las rutinas tradicionales en la comunidad originaria, en las que sí era posible la reproducción de la lengua; actividades, tiempos, distancias que no se prestaban a otra cosa que a conversar con sus pares, tal como recuerda una entrevistada:

Sí y después también, porque yo tenía unas primas que íbamos a buscar frutas al cerro, dihueñes, todas esas cosas y ahí hablamos todo el camino, todo el cerro y nos veníamos conversando y a veces ellas sabían más que mí, sí. Sí, entonces yo le enseñaba a ella o ella me enseñaba a mí, hablábamos fuerte, fuerte $[\ldots]$ antes de entrar al colegio era puro mapudungun [...] dice mi mami (F. H.).

(b) Otra actividad tradicional que se ve truncada por las dinámicas de la vida actual en la ciudad, en donde el tiempo no abunda y la lógica apunta a su maximización, con largas jornadas laborales y tiempos de viaje hacia y desde los trabajos, es tomar mate, instancia fundamental para el intercambio de experiencias y circulación de la lengua. Este espacio ha sido recuperado, en términos masivos, solo en el seno de agrupaciones indígenas, pero no siempre en la familia. (c) Se agrega también, y en cierta medida como consecuencia de lo anterior, la pérdida del control cultural (Bonfil Batalla 1983) que tienen los mapuches sobre un bien cultural como su lengua. Al estar insertos en una sociedad dominadora, sus prácticas no son capaces de reproducirse de modo autónomo: los trámites oficiales no se hacen en su lengua, las transacciones económicas tampoco, los medios masivos de comunicación no tienen programación en mapudungun, etc. En este punto, se debe recalcar el rol que juegan las estructuras de transición (organizaciones sociales mapuches de diversa índole) en la recuperación de estas redes sociales, tal como lo señala una entrevistada, refiriéndose a su participación en una agrupación de mujeres, en donde ellas reproducen actividades tan tradicionales como el telar, instancia en la que aprovechan de realizar intercambios en mapudungun.

(d) Otro factor que incide en esta ruptura de los circuitos tradicionales de enseñanza aprendizaje del mapudungun corresponde a la carencia de funcionalidad de la lengua en la sociedad, determinando un bajo estímulo para su aprendizaje y su enseñanza, tal como lo afirma otra entrevistada: "[...] ¿a una persona común y corriente, de qué le sirve saber mapudungun?, no le sirve de nada, si tú un idioma lo sabes y no lo practicas, se pierde [...]" (D. H.). Por un lado es eso, y por otro lado está el hecho de que el medio ambiente externo no lo hace necesario:

[...] aun cuando yo lo haya aprendido cuando chica, no sé po, si el mundo me está pidiendo saber inglés, y no tengo con quien practicar el idioma, porque no sé po, mi hermano no lo sabe, y [...] te casas y tu marido no lo sabe... tus compañeros de trabajo tampoco lo saben [...] (M. P.).

Y agrega, respecto de la condicionante del medio ambiente externo, al narrar su actual intención de aprender mapudungun: "[...] no es como una prioridad que tenga ahora, quizás mi prioridad sería aprender inglés, porque el medio te lo pide, el trabajo te lo pide [...]" (M. P.). Es decir, es capaz de identificar que si no se avanza en la promoción social de la lengua, no se saca nada con centrarse en sofisticar las estrategias y espacios para su aprendizaje (que es la tendencia 
identificada en el discurso de la élite intelectual mapuche). De esta manera, la falta de contexto también es un factor que ha cortado los circuitos de transmisión tradicional en las familias. Este discurso se ve reforzado, además, por transformaciones sociales y económicas. Por ejemplo, en la misma familia, incluso existiendo hablantes competentes, no resulta posible que se utilice cotidianamente la lengua nativa con fines prácticos, situación que ocurre en la comunicación entre las nuevas y antiguas generaciones y constituye un motivo de desincentivo del uso para las segundas y carencia de estímulo de aprendizaje para las primeras. Se instaura así el bloqueo de la circulación de la lengua en su medio ambiente natural por excelencia. Se produce entonces el efecto paradójico de que la baja competencia de las nuevas generaciones hace que las antiguas aprendan español y tengan menos incentivo para hablar mapudungun en sus casas, generándose así un círculo vicioso.

(e) En último término, otro factor que bloquea los circuitos tradicionales de reproducción es el cambio en las pautas de conducta propias de la construcción de género tradicional mapuche, las que se han visto afectadas por el rol de la mujer en la sociedad compleja actual. En particular, en un contexto urbano, pauperizado, característico de los grupos mapuches en la urbe, afecta también el papel que la mujer tiene en la socialización lingüística de sus hijos. En la sociedad tradicional mapuche le correspondía a la mujer un rol central en la reproducción de la cultura, y en particular de la lengua, dentro del núcleo familiar. En el fogón, en la cocina, espacio central de socialización de las familias mapuches, la mujer exponía a los hijos a la lengua. En la ciudad, las estructuras de expectativas que orientan su rol de género la obligan a salir del hogar para incorporarse al mercado laboral, impidiéndole ejercer a cabalidad como figura catalizadora de la lengua y la cultura en el hogar. Esto hace que la familia deje de ser un espacio de reproducción, que sus integrantes alcancen baja competencia o, definitivamente, que no se hable mapudungun en su seno.

\section{Conclusiones}

En lo relativo a la planificación lingüística, nos parece que tomar en cuenta la perspectiva de los saberes tradicionales acerca del mapudungun contribuiría a subsanar algunas de las principales dificultades con que se han enfrentado hasta ahora los esfuerzos de revitalización de esta lengua en contextos urbanos. De esta manera, se contribuiría, además, a revalorizar los conocimientos que la mayoría de los propios sujetos participantes o afectados por la planificación lingüística indígena pueden manifestar en torno a la lengua que forma parte de su identidad cultural. Gracias a esta perspectiva, los miembros de los pueblos indígenas podrían dejan de ser vistos como sujetos de intervención y pasar a ser concebidos como sujetos de acción, que pueden y deben incorporarse no solo al diagnóstico, sino que también a la solución de problemas relacionados con la lengua.

No pretendemos negar la importancia de los aspectos destacados por los especialistas indígenas, sino más bien deseamos llamar la atención sobre la necesidad de tener también en cuenta las percepciones que la mayoría de los miembros de los pueblos indígenas, esto es, quienes articulan sus reflexiones sobre el saber tradicional, tienen en torno a sus lenguas. Por último, esperamos haber contribuido a clarificar la importancia de que los especialistas indígenas se propongan, como todos los especialistas, efectuar una "clarificación ideológica" (Dauenhauer y Dauenhauer 1998, cit. en Field y Kroskrity 2009:26), es decir, un autoexamen crítico desde el punto de vista lingüístico-ideológico.

Por otra parte, hemos podido comprobar la naturaleza heterogénea de las ideologías acerca de la lengua que existen entre los mapuches (la heterogeneidad intrínseca de las ideologías lingüísticas es destacada, por ejemplo, por Woolard 1998), pues existen divergencias entre los discursos metalingüísticos articulados desde los saberes tradicionales y los de los especialistas, en cuanto al foco de la intervención. Los especialistas, probablemente influenciados por el modelo de las lenguas europeas y la cultura de la lengua estándar, ponen énfasis en aspectos como el grafemario unificado, la enseñanza formal en la escuela como lengua materna o la linealidad de los subprocesos de la planificación (primero planificación del corpus, luego planificación del estatus), entre otros, descuidando aspectos relativos al estatus, el prestigio y otras dimensiones socioculturales. Quienes enuncian sus posturas desde los saberes tradicionales, mientras tanto, subrayan la funcionalidad que necesariamente debe tener la lengua y lo importante que es atender a su promoción social y el mejoramiento de su 
estatus. En cuanto a su enseñanza, estos últimos actores sociales se muestran conscientes de la necesidad de que esta se inserte en los contextos naturales de transmisión que operan en la cultura mapuche (la comunidad y la familia), a pesar de que las condiciones actuales de la lengua en la ciudad dificultan la implementación de esta dinámica (la enseñanza está prácticamente monopolizada por la escuela, la EIB y los talleres de lengua, y la comunidad no tiene presencia como espacio cultural) y a pesar de que no ha habido mayor discusión al respecto en el nivel de los agentes planificadores oficiales.

Agradecimientos: En primer lugar, nuestro agradecimiento a todos quienes nos permitieron estar presentes en sus reuniones y aceptaron que conversáramos con ellas y ellos. En segundo término, agradecemos el apoyo de CONICYT (proyecto FONDECYT Iniciación 1110362), el Fondo de Investigación U-Cátedra Indígena de la Universidad de Chile (proyecto "Ideologías lingüísticas de los mapuches urbanos en torno al mapudungun") y la Vicerrectoría de Investigación y Desarrollo de la Universidad de Chile (proyecto SOC U-SOC11/11). También agradecemos la colaboración que los estudiantes miembros del SEPLAR prestaron durante la recolección de los datos etnográficos analizados en este trabajo. Finalmente, agradecemos a los evaluadores anónimos que contribuyeron a mejorar la calidad de este trabajo con sus comentarios y sugerencias.

\section{Referencias Citadas}

Amorós, C. 2008. Diferentes perspectivas en torno a la planificación lingüística. Actas del XXXVII Simposio Internacional de la Sociedad Española de Lingüística (SEL), editado por I. Olza, M. Casado y R. González, pp. 17-30. Servicio de Publicaciones de la Universidad de Navarra, Pamplona.

Anderson, J.D. 2009. Contradictions across Space-Time and Language Ideologies in Northern Arapaho Language Shift. En Native American Language Ideologies. Beliefs, Practices, and Struggles in Indian Country, editado por P.V. Kroskrity y M.C. Field, pp. 48-76. The University of Arizona Press, Tucson.

Bauer, L. y P. Trudgill (eds.) 1998. Language Myths. Penguin, London.

Blommaert, J. 2006. Language ideology. En Encyclopedia of Language \& Linguistics. Vol. 6, editado por K. Brown, pp. 510522. Segunda edición, Elsevier, Oxford.

Bonfil Batalla, G. 1983. Lo propio y lo ajeno: una aproximación al problema del control cultural. Revista Mexicana de Ciencias Políticas y Sociales 27:181-191.

Bourdieu, P. 2001. ¿Qué Significa Hablar? Tercera edición. Akal, Madrid.

CEP 2006. Estudio de Opinión Pública. Los Mapuche Rurales y Urbanos Hoy. CEP, Santiago.

Chiodi, F. y E. Loncón 1995. Por una Nueva Política del Lenguaje. Pewen, Temuco.

CONADI 2005. Primer Seminario Taller: Experiencias y conocimientos para el fortalecimiento y la promoción de las lenguas originarias. MIDEPLAN-CONADI, Santiago.

CONADI 2008. Perfil sociolingüistico de comunidades mapuche de la VIII, IX y X región. Fondo de Cultura y Educación, Santiago.

CONADI 2010. Catastro de hablantes de las asociaciones indígenas mapuche de la Región Metropolitana. CONADI, Santiago.
Feng, H. 2009. Different languages, different cultures, different language ideologies, different linguistic models. Journal of Multicultural Discourses 4:151-164.

Field, M.C. y P.V. Kroskrity 2009. Introduction: Revealing Native American language ideologies. En Native American Language Ideologies. Beliefs, Practices, and Struggles in Indian Country, editado por P.V. Kroskrity y M.C. Field, pp. 3-28. The University of Arizona Press, Tucson.

Foucault, M. 1966. Les Mots et les Choses. Une Archéologie des Sciences Humaines. Éditions Gallimard, Paris.

Gundermann, H., J. Canihuán, A. Clavería y C. Faúndez 2009. Permanencia y desplazamiento, hipótesis acerca de la vitalidad del mapuzugun. Revista de Lingüística Teórica y Aplicada 47:37-60.

Hornberger, N. 2006. Frameworks and models in language policy and planning. En An Introduction to Language Policy: Theory and Method, editado por T. Ricento, pp. 24-41. Blackwell, Malden.

House, D. 2002. Language Shift among the Navajos: Identity Politics and Cultural Continuity. The University of Arizona Press, Tucson.

INE 2013. Censo 2012. Resultados XVIII Censo de Población. Disponible en http://www.censo.cl/contenido/resultados_ censo_2012_poblacion_vivienda_tomosIyII.pdf.

Kroskrity, P.V. 2000. Language ideologies in the expression and representation of Arizona Tewa ethnic identity. En Regimes of Language: Ideologies, Polities, and Identities, editado por P.V. Kroskrity, pp. 329-359. School of American Research Press, Santa Fe.

Kroskrity, P.V. 2010. Language ideologies - Evolving perspectives. En Society and Language Use, editado por J. Jaspers, J. Östman y J. Verschueren, pp. 192-211. John Benjamins, Amsterdam/ Philadelphia.

Lagos, C. 2004. La vitalidad Lingüística del Mapudungún en Santiago de Chile. Sus Factores Determinantes y Consecuencias 
Socioculturales: Estudio Exploratorio. Tesis presentada para optar al grado de Magíster en Lingüística, Departamento de Lingüística, Universidad de Chile, Santiago.

Lagos, C. 2006. Mapudungún en Santiago de Chile: vitalidad, lealtad y actitudes lingüísticas. Lenguas Modernas 31:97-126.

Lagos, C. 2009. Acerca de la importancia de la promoción social y revitalización de las lenguas indígenas en Chile. Docencia 37:36-43.

Lagos, C. 2011. Construcción discursiva y representaciones sociales de los mapuches urbanos en torno a su lengua nativa. Lenguas Modernas 36:13-32.

Lagos, C. 2012a. El Mapudungún en Santiago de Chile. Editorial Académica Española, Madrid.

Lagos, C. 2012b. El mapudungún en Santiago de Chile: vitalidad y representaciones sociales en los mapuches urbanos. Revista de Lingüística Teórica y Aplicada 50:161-190.

Lagos, C. 2012c. Etnicidad y política pública en la recuperación de la lengua mapuche en el área pehuenche de Alto Bío Bío: vitalidad del chedungún y educación intercultural bilingüe. Ponencia presentada en el III Congreso Latinoamericano de Antropología, Santiago, Chile.

Lagos, C., C. Oyarzo, H. Mariano, D. Molina y F. Hasler 2009. Perfil etno- y sociolingüístico del mapudungún en Santiago de Chile. Lenguas Modernas 34:117-137.

Lagos, C., M. Espinoza y D. Rojas 2013. Mapudungun according to its speakers: Mapuche intellectuals and the influence of standard language ideology. Current Issues in Language Planning 14:403-418.

Loncón, E. 2002. El Mapudungún y los Derechos Lingüísticos del Pueblo Mapuche. Working Paper Series, $\mathrm{N}^{\circ}$ 4, Nuke Mapuförlaget

Mariano, H., D. Molina, C. Oyarzo, C. Lagos y F. Hasler 2010. ¿Mongeley kam mongelelay chi mapudungun waria mew? Vitalidad y representación social del mapudungún en Santiago de Chile. Romanitas 4:42-69.

Mariano, H., L. Curin, F. Hasler, E. Antileo, A. Salazar, A. Ahumada, S. Mayo, C. Vargas, K. Vega, F. Curin y M. Huaiqui 2013. Kom kim mapudunguain waria mew A.1.2. Ediciones Comunidad de Historia Mapuche, Santiago.

Milroy, J. 2001. Language ideologies and the consequences of standardization. Journal of Sociolinguistics 5:530-555.

Munizaga, C. 1961. Estructuras transicionales en la migración de los araucanos de hoy a la ciudad de Santiago de Chile. Notas del Centro de Estudios Antropológicos, $N^{\circ}$ 6. Universidad de Chile, Santiago.

Niedzielski, N. y D. Preston. 2003. Folk Linguistics. Mouton de Gruyter, Berlin/New York.
Painemal, N. 2007. Acerca de las lenguas indígenas en el país. CONADI, Santiago.

Pasquale, M. 2011. Folk beliefs about second language learning and teaching. AILA Review 24:88-99.

Paveau, M.-A. 2011. Do non-linguists practice linguistics? An anti-eliminative approach to folk theories. AILA Review 24:40-54.

Preston, D. 1994. Content-oriented discourse analysis and folk linguistics. Language Sciences 16:285-330.

Ricento, T. 2006. Theoretical Perspectives in Language Policy: An Overview. En An Introduction to Language Policy: Theory and Method, editado por T. Ricento, pp. 3-9. Blackwell, Malden.

Romaine, S. 2007. Linguistic diversity and language standardization. En Handbook of Language and Communication: Diversity and Change, editado por M. Hellinger y A. Pauwels, pp. 685-713. Mouton de Gruyter, Berlin.

Salas, A. 1985. Hablar en mapudungún es vivir en mapuche. Especificidad de la relación lengua-cultura. Revista de Lingüística Teórica y Aplicada 25:27-35.

Sánchez, G. 1996. Estado actual de las lenguas aborígenes de Chile. Boletín de la Academia Chilena de la Lengua 71:68-87.

Schieffelin, B.B. 2000. Introducing Kaluli Literacy: A chronology of influences. En Regimes of Language: Ideologies, Polities, and Identities, editado por P. V. Kroskrity, pp. 293-327. School of American Research Press, Santa Fe.

Silverstein, M. 1998. The uses and utility of ideology. A commentary. En Language Ideologies. Practice and Theory, editado por B.B. Schieffelin, K.A. Woolard y P.V. Kroskrity, pp. 123-145. Oxford University Press, Oxford.

Van Dijk, T. 1998. Ideology. A Multidisciplinary Approach. SAGE Publications Ltd., London.

Vergara, A. y A. Salazar 2012. Didáctica de lenguas originarias: La experiencia del internado lingüístico como instrumento para la revitalización de la lengua mapuche. En Libro de las Terceras Jornadas Internacionales de Didáctica de Lenguas y Literatura. GEISE, Bariloche.

Vergara, J.I. y H. Gundermann 2005. Descripción del Contexto Sociolingüístico en Comunidades Indígenas de Chile. Programa EIB MINEDUC - Programa Orígenes, Santiago.

Wilton, A. y M. Stegu 2011. Bringing the 'folk' into applied linguistics: An Introduction. AILA Review 24:1-14.

Wittig, F. 2009. Desplazamiento y vigencia del mapudungún en Chile: un análisis desde el discurso reflexivo de los hablantes urbanos. Revista de Lingüística Teórica y Aplicada 47:135-155.

Woolard, K. A. 1998. Introduction: Language Ideology as a Field of Inquiry. En Language Ideologies. Practice and Theory, editado por B.B. Schieffelin, K.A. Woolard y P.V. Kroskrity, pp. 3-47. Oxford University Press, Oxford.

\section{Notas}

1 Nos referimos a los proyectos de investigación señalados en la sección "Agradecimientos".
2 Esta y las demás citas de obras en lengua inglesa han sido traducidas por los autores del presente artículo. 
